\title{
OPINIÃO DOS ASSOCIADOS QUANTO À PARTICIPAÇÃO DA ASSOCIAÇÃO BRASILEIRA DE ENFERMAGEM EM ORGANIZAÇÕES INTERNACIONAIS
}

OGUISSO, T. - Opinião dos associados quanto à participação da Associação Brasileira de Enfermagem em organizações internacionais. Rev. Bras. Enf.; DF, 33:102-120, 1980.

\section{INTRODUÇAO}

Üma das finalidades da Associação Brasileira de Enfermagem (ABEn) é "promover o interrelacionamento com associações congêneres, nacionais, estrangeiras e internacionais, visando o aprimoramento e a divulgação da enfermagem brasileira".

Tal preceito vem sendo seguido desde 1929, apenas três anos após a fundação da Associação, quando foi aceita como membro do Conselho Internacional de Enfermeiras (CIE ou International Council of Nurses (ICN); em 1955, após vencer inúmeras difículdades e problemas, foi recebida como "membro aderante" pelo Comitê Internacional Católico de Enfermeiras e Assistentes Médico-Sociais (CICIAMS) e, finalmente, em 1969 foi convidada a filiar-se à Federação Panamericana de Enfermeiras (OS) (FEPAEN), o que se efetivou em 1970.
Cada uma dessas entidades internacionais tem estatuto próprio e não aceita filiação de enfermeiros individualmente, mas somente de um órgão representativo de cada país. Por ser a única entidade de classe dos enferneiros existente nessas diversas ocasiões, somente a ABEn está filiada às três entidades internacionais citadas.

Essa filiação, ao mesmo ternpo que possibilita intercâmbio cultural e social através de publicações e reuniões científicas, favorece a divulgação da enfermagem brasileira no exterior, e ccm isso o próprio desenvolvimento da profissãc.

Entretanto, a manutenção dessa filiação vem sendo motivo de preocupaçāo para a ABEn devido ao ônıı financeiro que acarreta.

Em 1978, eram as seguintes as cor.tribuições devidas às entiaddes internacionais:

CIE - SF $\$ 2,20$ (dois e vinte francos suíços) ou Cr\$30,60 (trinta cruzeiros e sessenta centavos "per capita";

* 1. Tesoureira da Associação Brasileira de Enfermagem da ABÉn, quadriênio 1976-80. 
OGUISSO, T. - Opinião dos associados quanto à participação da Associação Brasileira de Enfermagem em organizaçōes internacionais. Rev. Bras. Enf.; DF, 33:102-120, 1980.

CICIAMS - Associações com 25 a 1000 associados - FB $\$ 2.645$ (dois, seiscentos e quarenta e cinco francos belgas) ou Cr\$2.098,46 (dois mil e noventa c oito cruzeiros e quarenta e seis centavos);

Associações com 101 a 400 sócios FB $\$ 5.290$ (cinco mil e duzentos e noventa francos belgas) ou Cr\$ 4.136,02 (quatro mil, cento e noventa e seis cruzeiros e noventa e dois centavos);

Associações com mais de 400 associados - FB \$ 13,25 "per capita" ou Cr\$ 10,51 (dez cruzeiros e cinqüenta e un centavos).

FAPAEN - Anuidade fixa de USS 600 (seiscentos dólares americanos) ou Cr\$ 14.274,00 (quatorze mil, duzentos e setenta e quatro cruzeiros).

Essas conversões para a moeda nacional foram feitas ao câmbio oficial do dia 26 de abril de 1978, segundo as seguintes cotaçōes para venda do Eanco Central do Brasil: franco suíco a $\$ 13,91952$; franco belga a $\$ 0,79337$ e dólar americano a $\$ 23,79$.

As importâncias a serem remetidas para as duas primeiras entidades correspondem ao produto do valor "per capita" respectivo multiplicado pelo número de associados e acrescido das taxas de remessa, comissões e outras despesas bancárias.

Nos últimos anos, o crescimento da ABEn encontrou uma fase quase estacionária, conforme se pode constatar no Relatório da Tesouraria do período 1977-78. Apesar desse crescimento lento e paulatino, em 1978, finalmente, foi ultrapassada a casa dos 5.000 associados, meta almejada por esta diretoria. Pela primeira vez na história da $A B E n$, foi atingido tal número, o que representa cerca de $40 \%$ do total de 12.381 enfermeiros e obstetrizes inscritos no Conselho Federal de Enfermagem, no mesmo ano. Com esse aumento no número de associados, aumentam também os encargos financeiros da ABEn, tornando sua situação econômica cada vez mais difícil de ser solucionada. Eis que a ABEn, declarada de utilidade pública pelo Decreto Federal n. ${ }^{\circ} 31.417$, de 9 de setembro de 1952, goza de isenções tributárias e recebe subvenções e doações, principalmente de órgãos públicos ou autárquicos. Considerando a situação sócio-política e econômica do país, não haveria justificativa para remessa de dinheiro em tal volume para entidades internacionais. Poderia parecer contradição, de um lado pedir e receber doações e, de outro, remeter contribuições para o exterior.

Considerando a necessidade de sc conhecer melhor o grau de interesse dos associados na manutenção da filiação a entidades internacionais, a Tesouraria propôs, e a Diretoria da ABEn aceitou, fosse feito um estudo sobre o assunto.

Assim, na reunião da Diretoria da ABEn em junho de 1978, a $1 .^{\mathrm{a}}$ Tesoureira assumiu a responsabilidade pela elaboração deste trabalho de pesquisa a fim de poder oferecer sugestões, fundamentadas no que pensam os associados, quanto ao problema da filiação.

Se houver interesse em sua manutenção, a ABEn deverá arcar com o ônus dessa filiação ou então estudar e propor novas medidas.

São, portanto, objetivos deste trabalho:

1. verificar se os associados consideram importante a filiação da $A B E n$ a entidades internacionais;

2. verificar se há relação entre:

2.1. a) participação do associado em cargo de diretoria da ABEn e freqüência a seus congressos;

b) participação do associado em cargo de diretoria da ABEn e freqüência a Congressos Internacionais;

2.2. c) tipo de atividade ou função exercida pelo profissional e exercício de cargo de diretoria da $A B E n$; 
OGUISSO, T. - Opiniāo dos associados quanto à participação da Associação Brasileira de Enfermagem em organizações internacionais. Rev. Bras. Enf.; DF, 33:102-120, 1980.

d) tipo de atividade ou função exercida pelo profissional e freqüência a congressos:

2.3. e) época de formação do profissional e opção por uma determinada organização internacional de enfermagem;

3. averiguar se os associados concordariam em contribuir com uma complementação de anuidade para manuitenção da filliação da ABEn a entidades internacionais $\mathrm{e}$, em caso positivo, para qual das entidades.

\section{REVISÃO DA LITERATURA}

No livro "Associação Brasileira de Enfermagem 1926-1976, Documentário", CARVALHO (1976) relata minuciosamente as dificuldades que a ABEn enfrentou para manter sua fillação a essas organizaçōes internacionais, desde 1929. Segundo essa autora, em 1947, há, portanto 32 anos a Associação contava com apenas duzentas associadas. Dessas, cento e doze compareceram ao I Congresso Nacional de Enfermagem, em São Paulo e, apesar de número tão reduzido, corajosamente recomendaram à Associação para que oferecesse o Brasil para sede do $\mathrm{X}$ Congresso Quadrienal de Enfermagem, do Conselho Internacional de Enfermeiras, que foi realizado em 1953, no Rio de Janeiro.

Filiar-se ao CIE, em 1929, como primeira associação de enfermeiras da América do Sul, foi realmente uma grande e precoce conquista para as brasileiras. Porém, logo se sentiu a responsabilidade financeira dessa conquista.

Com a adesão ao CICIAMS, o problcma aumentou. Para tentar enfrentálo, de 1955 a 1965, segundo essa mesma autora, ficou estabelecido que cada associado deveria declarar, no ato do pagamento da anuidade da ABEn, para qual entidade internacional, CIE ou CICIAMS, ou ambas, desejava pertencer. Nesse último caso, deveria pagar uma taxa adicional. Entretanto, já antes de 1950, o CICIAMS contava com adesões de enfermeiros brasileiros, que haviam inclusive participado de seus congressos e até apresentado trabalho em tema oficial.

RESENDE (1961) considera que um dos fatores que conseguiu interessar maior número de enfermeiros, em 1958 e 1959, foi o fato da ABEn ter se filiado às duas instituições internacionais de enfermagem.

No "Relatório da Reunião do Conselho Diretor do ICN" RESENDE (1963) afirma que até 1950, a maioria dos associados nada sabia da filliação da ABEn ao CIE, e que foram os preparativos para o 10. ${ }^{\circ}$ Congresso Quadrienal de 1953 que o tornaram conhecido dos membros. Essa autora prossegue assinalando que em 1956 houve proposta para a transformação da ABEn em Federação para permitir guardar a unidade nacional e possibilitar a dualidade de filiação internacional - ao CIE e ao CICIAMS. Definiu como membro ativo para o CIE, o associado que se filiasse ou se registrasse no setor CIE, e para - CICIAMS, o que nele se registrasse. Os membros do Conselho Diretor do CIE, ante essa explanação da autora, demonstraram apreensão no caso em que assumisse a presidência da $\mathrm{ABEn}$ uma enfermeira filiada apenas ao setor CICIAMS, quando então não estaria ela representando a ABEn junto ao CIE. Argumentou então, a autora, que estava representando na ocasião a Presidente da $A B E n$, que a $A B E n$ não queria se dividir para efeito de filiação internacional, para não se enfraquecer. Também não queria contrariar as aspirações e direitos de seus associados de serem representados pela Associação, em mais de uma Federação Internacional, desde que essas Federações não conflitassem quanto aos objetivos profissionais. 
OGUISSO, T. - Opinião dos associados quanto à participação da Associação Brazileira de Enfermagem em organizaçōes internacionais. Rev. Bras. Enf.; DF, 33:102-120, 1980.

AYRES (1965) conclui seu Relatório de participação como delegada oficial, representando a ABEn, no XIII Congresso Quadrienal do CIE, realizado em Frankfurt-Alemanha, em 1965, dizendo que gostaria, de ajudar a Diretoria da ABEn a encontrar meios financeiros para manter a fillação com o CIE, porque achava de importância capital para a Enfermagem no Brasil ter voz e voto em uma Federação Internacional que presidia os destinos da Enfermagem no mundo.

Passados tantos anos, 'é possível que muitos associados ainda hoje desconheçam que a $A B E n$ esteja contribuindo para três organizações internacionais, com uma taxa anual variável, de acordo com o número de associados. Essa despesa, cada vez mais vultosa, vem sendo deduzida da receita anual e, portanto, inclusive do "per capita" enviado pelas Seções.

Depois de 1965, com a reforma do Estatuto, o capítulo sobre a cooperação com associações internacionais passou a constar como um dos meios para a ABEn alcançar seus objetivos e 0 assunto passou a ser tratado diretamente pela diretoria. Atualmente, com outra reforma do Estatuto, ocorrida em 1976, constitui uma das finalidades da ABEn o interrelacionamento com associações congêneres, nacionais, estrangeiras e internacionais.

Apesar de todas essas reformas estatutárias, a situação de relacionamento com aquelas instituições internacionais de enfermagem continua a mesma, pois a ABEn, como membro, deve contribuir com a cota anual por elas estabelecidas.

\section{METODOLOGIA}

\section{1) População}

Considerando a dificuldade na realização de uma consulta geral a todos os asšociados da ABEn sobre o interesse na manutenção da fillação a entidades internacionais, o que demandaria sobrecarga de trabalho às diretorias das Seções e Distritos e demora na óbtenção de dados, foi escolhido como população deste estudo os membros efetivos e especiais que comparecessem ao $\mathrm{XXX}$ Congresso Brasileiro de Enfermagem, realizado em Belém do Pará, no período de 16 a 23 de julho de 1978.

De acordo com o Regimento Interno desse Congresso, puderam se inscrever como membros efetivos - os enfermeiros, obstetrizes e técnicos de enfermagem, quites com a Tesouraria, assim como os enfermeiros estrangeiros credenciados pela sua própria associação de classe. Como membros especiais puderam se inscrever os estudantes dos dois últimos periodos do tronco profissional comum, associados à ABEn e também os estudantes de curso de graduação dos demais períodos e do curso Técnico de Enfermagem, desde que oficialmente credenciados pelo Diretoria da respectíva instituição de ensino, no máximo três por curso.

De um modo geral, a freqüência aos congressos possibilita atualização de conhecimentos profissionais; porém, essa participação nem sempre é fácil. Nesse ano, o Congresso Brasileiro de Enfermagem foi realizado na Capital de um Estado situado no extremo norte do País, o que dificultou para muitos a locomoção, dada a distância, a dificuldade dos meios de transporte e o custo da viagem.

A maioria dos enfermeiros, como ocorre com outros profissionais, está localizada no eixo Rio-São Paulo, aumentando a dificuldade para grande número de associados. por esse motivo, que aqueles que, superando essas dificuldades, compareceram ao Congresso estivessem realmente motivados a participar e aproveitar das reuniōes científicas. 
OGUISSO, T. - Opinião dos associados quanto à participação da Associação Brasileira de Enfermą̧em em organizações internacionais. Rev. Bras. Enf.; DF, 33:102-120, 1980.

Geralmente, associados que costumam freqüentar congressos nacionais estão acostumados com a dinâmica desses conclaves e são estimulados a participar de congressos internacionais. Supõe-se que esses associados conheçam melhor os objetivos da ABEn, e a interrelação existente entre ela e os organismos internacionais.

Por outro lado, a realização de Assembléias de Delegados, por ocasião dos congressos, é outro fator que contribui para que haja participação de membros representativos da classe, tais como os membros natos - que são as Presidentes das Seções e Distritos da ABEn e os delegados oficiais das Seções; e, os membros eleitos, que são os delegados mais votados em assembléias estaduais ou gerais, na proporção de um para cada oitenta membros efetivos.

Se os membros natos e eleitos da Assembléia de Delegados são considerados líderes da classe em seus respectivos Estados e Distritos, a população de membros efetivos da ABEn, presentes a uma Assembléia de Delegados deve representar, com muita possibilidade de acerto, o pensamento dos enfermeiros, em geral.

\section{2) Método}

O instrumento utilizado para a coleta de dados foi o questionário (Anexo I). A opção por este método foi feita tendo-se em conta a facilidade de aplicação.

Considerando os objetivos do estudo, o questionário foi elaborado para levantar não só os dados mínimos indispensáveis como outros para assegurar a máxima autenticidade das respostas.

Os itens constantes do questionário correspondem a:

a) dados de identificação do associado, apenas quanto à Seção ou Distrito a que pertence; profissão (enfer- meira, obstetriz, técnico de enfermagem ou estudante de enfermagem); atividade principal (se hospitalar, ambulatorial, ensino, administração, etc.); tempo de permanência como associado; se houve interrupção na filiação à Associação; se ocupa ou ocupou cargo na diretoria da ABEn. Em caso positivo, que cargos, em que nível (nacional, estadual ou distrital) e qual o período de mandato;

b) participação do associado em congressos promovidos pela ABEn, nos últimos dez anos, e em congressos internacionais;

c) opinião do associado quanto à importância da filiação da ABEn a entidades internacionais;

d) concordância ou não do associado em pagar complementação de anuidade e suas opções pelas entidades internacionais.

Esses itens incluem sete questões fechadas e três abertas. As questões abertas referem-se ao nome da instituição de trabalho ou de ensino, justificativas para a importância da filiação da ABEn a essas organizações e nome do cargo, nível e período de mandato do cargo eletivo ocupado na diretoria dá Associação.

$\mathrm{Na}$ verdade, a pergunta sobre o nome da instituição de trabalho só foi feita a fim de tentar garantir uma resposta a mais adequada possível quanto à principal atividade exercida. Para isso, foi feita uma rápida revisão em todos os questionários a fim de conferir nome da instituição com o tipo de atividade principal do informante. Se o nome da instituição era hospitalar, mesmo que a enfermeira exercesse atividade de educação em serviço, por exemplo, sua função principal foi considerada hospitalar e não de ensino. Somente as que declararam trabalhar em Escola ou Faculdade, a atividade foi classificada como de "ensino". A atividade "administração e assessoria" fol aceita para aqueles que declararam trabalhar 
OGUISSO, T. - Opiniāo dos associados quanto à participação da Associação Brasileira de Enfermagem em organizações internacionais. Rev. Bras. Enf.; DF, 33:102-120, 1980.

instituição de ensino ou de serviço, considerando que poderiam estar em cargo de direção. Essa revisão não foi muito útil para o fim pretendido inicialmente, mas serviu para completar vários questionários que se apresentavam sem identificação quanto ao nome da Seção ou Distrito, através do nome da instituição de trabalho ou de ensino.

Após essas revisões nos questionários preenchidos, os dados foram processados em computador IBM da Faculdade de Medicina de Botucatú, da Universidade Estadual Paulista (UNESP).

O estudo piloto foi apicado em trinta enfermeiras, quase todas associadas à ABEn, entre as que trabalhavam no Hospital das Clínicas da Faculdade de Medicina, da Universidade de São Paulo (USP), na Escola de Enfermagem da USP e alunas do curso de Saúde Pública para graduados em Enfermagem, da Faculdade de Saúde Pública da USP. Essas alunas eram todas enfermeiras procedentes dos Estados do Pará, Goiás, Minas Gerais, Ceará, Rio Grande do Norte, Sergipe, Santa Catarina e São Paulo.

Após a aplicação desse pré-teste, o questionário foi parcialmente reformulado, a fim de torná-lo mais claro e adequado.

Foram elaborados 1.500 questionários, calculando-se que seria mais ou menos este o número de associados a comparecerem ao $\mathrm{XXX}$ Congresso, em Belém do Pará, com base em experiências anteriores e considerações sobre a distância e o custo da viagem.

Os questionários seriam entregues pela Subcomissão de Registro do $\mathrm{XXX}$ Congresso, junto com a ficha de inscrição do associado efetivo ou especial, com orientação para ser devolvido junto com a mesma, a fim de receber a pasta do Congresso. Não foram incluídos os sócios observadores, institucionais, honorários ou beneméritos, por não constituirem categorias profissionais previstas no Estatuto da ABEn.
Foi feita orientação à Coordenadora e monitoras da Subcomissão referida, dando os esclarecimentos necessários quanto ao procedimento, num total aproximado de trinta minutos. Esclarecimentos eventuais posteriores foram dados pessoalmente pela autora deste estudo, que se encontrava no recinto do Congresso por pertencer à Diretoria da ABEn, promotora do referido evento.

Do total de 1.500 questionários, foram distribuídos 1.300 e devolvidos 1.127 preenchidos $(86,7 \%)$.

O Quadro Demonstrativo de Membros participantes do XXX Congresso Brasileiro de Enfermagem, segundo qualificação, número e procedência, publicado na Revista Brasileira de Enfermagem, vol. 31, n. ${ }^{\circ} 3$, de julho a setembro de 1978 , página 398 , mostra que a população utilizada neste estudo deveria ser de 1.094 membros efetivos e 231 especiais, num total de 1.325 congressistas dessas duas categorias. Desse total, 25 não receberam questionário; 173 receberam, mas não devolveram; e $\mathbf{1 . 1 2 7}$ receberam e devolveram-no preenchido, ou seja, $85 \%$ dos presentes.

\section{3) Definição de termos}

CIE - Conselho Internacional de Enfermeiras, é uma federação que-congrega associações nacionais de enferTreiras de 87 países. também conhecido como ICN, sigla do original em inglês "International Council of Nurses'. Sua sede atual está localizada em Genebra, Suiça. a organização mais antíga no campo da saúde. Fol fundado em 1899. O Conselho está organizado e funciona sem fazer distinção alguma de nacionalidade, raça, religião, cor, posição política, sexo ou condição social.

CICIAMS - Comitê Internacional Católíco de Enfermeiras e Assistentes Médico Sociais. Essa entidade surgiu com o objetivo de estimular em todos os países a criação e o desenvolvimento 
OGUISSO, T. - Opinião dos associados quanto à participação da Associação Brasileira de Enfermagem em organizações internacionais. Rev. Bras. Enf.; DF, 33:102-120, 1980.

das associações profissionais católicas, a fim de assegurar 0 apoio moral e espiritual às enfermeiras e assistentes médico-sociais católicas, visando ao mesmo tempo seu aperfelçoamento técnico. Sua sede atual está localizada em Bruxelas, Bélǵica.

FEPAEN - Federação Panamericana de Enfermeiras(os). Foi oficialmente constituída em 1970, na Venezuela. Por Estatuto, a sede da Federação é itinerante, localizando-se no país de residência da presidente eleita.

"Per capita" - Taxa votada e aprovada pela Assembléla de Delegadas, órgão superior de deliberação da ABEn, a ser deduzida da anuidade que o associado paga ao Distrito ou à Seção Estadual e recolhida à Tesouraria da ABEn Central, dando a esse indivíduo o direito de ser membro da ABEn.

As entidades internacionais também estabelecem uma taxa "per capita" para que cada organização membro a elas filiada contribua com um valor correspondente ao número de associados existente.

Associados da ABEn - Podem ser enfermeiros, obstetrizes, técnicos de enfermagem e estudantes dos cursos de graduação em enfermagem matriculados nos dois últimos períodos do trónco profissional comum e que estejam quites com a Tesouraria.

Distritos - São os núcleos constituídos por um mínimo de quarenta enfermeiros e/ou outros elementos das categorias previstas no Estatuto, e que possam ser admitidos na ABEn. Para constituição do Distrito, esses quarenta ou mais profissionals residentes na reglão devem se organizar e solicitar, por escrito, a sua criação, o que se efetivará pela autorização da Assembléla Estadual de Delegados (AED) da Seção e pela homologação da Assembléia de Delegados (AD). As sedes dos Distritos são localizadas nos municípios onde forem criados.
Seçōes - São os núcleos da ABEn, constituídos pelos distritos localizados numa Unidade da Federação, com sede na Capital do Estado. Desde a última reforma do Estatuto, em 1976, toda Seção Estadual deverá ter pelo menos, um Distrito, o da Capital.

Assembléia de Delegados - E o órgão superior de deliberação da ABEn, a nivel central. Reune-se anualmente por ocasião dos congressos. A nível estadual chama-se Assembléia Estadual de Delegados (AED) e, a nível distrital, Assembléla Geral (AG), que é constituída de todos os associados do Distrito. As AED são constituídas de delegados escolhidos pelos associados do distrito, reunidos em $A G$.

Congressos Brasileiros ou Nacionais - São os conclaves promovidos anualmente pela Associação Brasileira de Enfermagem, desde 1947.

Congressos Internacionais - São os promovidos pelo Conselho Internacional de Enfermeiras (CIE), pelo Comitê Internacional Católico de Enfermeiras e Assistentes Médico-Sociais ou pela Federação Panamericana de Enfermeiras(os).

\section{4) Limitações do estudo}

A realização do presente estudo fol em parte dificultada pelos seguintes fatores:

a) grande número de itens do questínário não respondido pelos congressistas que o devolveram;

b) falha no próprio questionário que fol mimeografado em uma única folha, com utilização da frente e verso do papel. Muitos congressistas só preencheram o anverso, esquecendo-se da parte mais importante das perguntas que constavam no verso.

c) o sistema de inscrição ao congresso se realizar em sua quase totalidade nos dois primeiros dias, com grande acúmulo de pessoas junto a0s 
OGUISSO, T. - Opinião dos associados quanto à participação da Associação Brasileira de Enfermagem em .organizaçōes internacionais. Rev. Bras. Enf.; DF, 33:102-120, 1980.

balcões da Subcomissão de Registro e especialmente nos locais de entrega das pastas no congresso. Essa sobrecarga de trabalho dificultou o controle por parte das monitoras, especialmente quanto ao preenchimento do questionário, e pode ter contribuído também para algum extravio ou falta de devolução do quesionário.

\section{ANALISE E DISCUSSÃO DOS RESULTADOS}

\section{Características da população}

A Tabela 1 mostra a importância dos congressistas por Seção, de acordo com 0 ano de filiação à ABEn. Levouse em consideração apenas a Seção Estadual, incluídos os Distritos, a fim de facilitar a tabulação, mesmo porque apenas seis Seções do total de vinte e uma possuem Distritos subordinados. As Seções que apresentaram as maiores delegações foram as de São Paulo, a do Pará - sede do congresso, e a do Rio de Janeiro, com mais de uma centena de congressistas cada uma. Do total de 1.127 associados que devolveram os questionários preenchidos, a maioria, isto é, 698 membros $(61,9 \%)$, refere ter se associado após 1971. Cumpre salientar que 109 membros presentes $(9,7 \%)$ estão associados há dezoito anos ou mais.

A Tabela 2 apresenta os níveis dos cargos de Diretoria ocupados pelos congressistas na ABEn, em qualquer época, por Seção. Os níveis dos cargos podem ser: nacional, estadual e municipal, correspondendo à ABEn Central, à Seção ou a um Distrito, respectivamente. Duzentos e quatro, ou seja $18,1 \%$, dos congressistas pesquisados exerceram ou exercem cargos de Diretoria em um ou mais niveis, em épocas sucessivas ou simultâneas. No que se refere à procedência dos duzentos e quatro informantes que ocuparam cargos de diretorias, dos diversos níveis, trinta $(14,7 \%)$ per- tencem à Seção do Rio de Janeiro. Em segundo lugar, contribuiu com elementos para cargos de diretoria a seção São Paulo, com vinte e dois associados $(10,8 \%)$ e em seguida, a Seção Pará, com vinte um $(10,3 \%)$ e Minas Gerais com dezesseis $(7,8 \%)$. Com exceção da Seção Rio Grande do Norte, todas as demais contavam entre seus representantes, que responderam ao questionário, com elementos que pertencem ou já pertenceram à diretoria da ABEn.

A Tabela 3 mostra o total de congressistas distribuído por categoria, época de formação e procedência por Seção. Os enfermeiros, naturalmente, atingem a maior parcela com 881 representantes $(78,1 \%)$, seguidos dos estudantes de enfermagem com 179 $(15,8 \%)$. Das 37 obstetrizes que compareceram, a maioria tinha também curso de enfermagem. Por essa razão, a categoria profissional foi denominada "enfermeira obstétrica" e não "obstetriz". Quanto à procedência dos congressistas, especialmente dos enfermeiros formados após 1970, a maioria provinha de São Paulo com 158 (17,9\%), seguido do Pará $(14,5 \%)$ e do Río de Janeiro $(13,8 \%)$. Dos estudantes de enfermagem, o maior número de representantes procedeu das Seções Rio Grande do Norte e Golás, com 27 $(15,0 \%)$ cada um. Em segundo lugar, São Paulo, com 25 representantes $(13,9 \%)$ e o Pará, com $15(8,3 \%)$. Das Seções Sergipe, Minas Gerais, Distrito Federal, Paraná e Santa Catarina não houve representação estudantil no congresso. Quanto às 37 enfermeiras obstétricas, a maioria procedia da seção Ceará, com onze representantes $(29,7 \%)$ seguido de São Paulo com sete $(18,9 \%)$.

A Tabela 4 relaciona a principal função ou funções declaradas pelos congressistas com a respectiva procedência por Seção. Embora fosse solicitado que indicasse no singular, a principal função, cento e cinqüenta e oito congressistas $(14,0 \%)$ assinalaram duas ou 
OGUISSO, T. - Opiniāo dos associados quanto à participação da Associação Brasileira de Enfermagem em organizações internacionais. Rev. Bras. Enf.; DF, 33:102-120, 1980.

mais atividades. Essas funções foram reunidas em grupos de cuas, para facilitar a tabulação. Por falha no questionário, os estudantes de enfermagem também responderam a essa parte. A falha, inclusive. ocorreu tambím no pré-teste, que foi aplicado em trinta enfermeiras e nenhum estudante. Dos 179 estudantes que devolveram o questionário, a maioria, ou respondeu assinalando o item "não exerce a profissão", que apresentou um índice elevado, isto é, $7,8 \%$ do total de respostas, ou deixou de assinalar o item, o que representa $11 \%$ do total.

De acordo com a principal função ou funções exercidas pelos congressistas, observa-se que os da área hospitalar são os mais freqüentes, ou seja 367 ou $32,6 \%$ do total, seguidos dos que exercem atividades na área de ensino com $140(12,4 \%)$ e da área de administração e assessoria com $122(10,8 \%)$.

Mesmo somando todas as opções assinaladas conforme a Tabela 4, a atividade hospitalar foi a opção mais cotada, com 465 ou $35,9 \%$ do total, seguida da área de ensino com $235(18,2 \%)$ e administração, com 201 opções $(15,5 \%)$ como consta no Quadro I.

Observando-se o Quadro I, verificase que nas três áreas mais assinaladas pelos informantes, ou seja, hospitalar, ensino e administração, a Seção São Paulo lidera nas duas primeiras, seguida pelas Seções Rio de Janeiro e Pará. Entretanto, na atividade administração e assessoria, a Seção Rio de Janeiro contribuiu com a maior parcela das opções assinaladas, seguida por São Paulo e Pará. A atividade ambulatorial, entretanto, encontrou na Seção Pará o maior número de congressistas que responderam ser essa a atividade principal.

2. Participação do associado em congressos

A Tabela 5 apresenta a participação em congressos de Enfermagem das pessoas que responderam ao questionário. Foram numerados os dez últimos eventos para serem assinalados. Mesmo aqueles que não assinalaram a participação em nenhum dos congressos, de 1968 a 1977, na verdade estavam participando de um, o de 1978. Excluindo-se esses últimos, no total de 473 congressistas $(42 \%)$, obteve-se como resultado que 236 (21\%) só participaram de um conclave anteriormente. A maioria, isto é, $333(29,5 \%)$ dos que responderam ao questionário, participaram de 2 a 5. Desdobrando-se a faixa desses 333 informantes, verifica-se que $137(12,2 \%)$ responderam ter participado de 2 congressos; $106(9,4 \%)$ de três, $47(4,2 \%)$ de quatro e $43(3,8 \%)$ de cinco. Apenas cinco $(0,4 \%)$ informaram ter participado dos dez últimos congressos.

Das Seções de São Paulo e Rio de Janeiro procederam as maiores delegações, ambas com mais de uma centena de participantes de um ou mais congressos anuais. A Seção do Pará colocase, pelo total geral, em segundo lugar, porém há 91 informantes que participavam pela primeira vez, talvez dada a facilidade do congresso ter sido realizado na própria Seção. Excluindo-se, pois, a coluna dos que informaram não ter participado de congresso algum dentre os enumerados de 1968 a 1977, além das três Seções já citadas, as maiores delegações de congressistas veteranos procediam da Bahia e Minas Gerais. Com a Seção Ceará ocorreu fato semelhante ao da Seção Pará, pois o total geral é de 69 congressistas, mas 36 participavam pela primeira vez.

A Tabela 6 apresenta o nivel de participação dos informantes em congressos internacionias. Do total de 1.127 congressistas, $197(17,5 \%)$ Já participaram de um ou mais conclaves internacionais usufruindo, pois, do fato da ABEn estar filliada a essas organizações. São Paulo, Rio de Janeiro e Bahla são as Seções que contribuiram com maior número de 
OGUISSO, T. - Opiniāo dos associados quanto à participação da Associação Brasileira de Enfermagem em organizaçōes internacionais. Rev. Bras. Enf.; DF, 33:102-120, 1980.

freqüentadores desses eventos. Em quarto lugar, colocam-se três Seções: Pernambuco, Minas Gerais e Distrito Federal, com 13 congressistas, cada uma, que já participaram de congressos internacionais.

3. Opinião dos associados quanto à filiação da ABEn

A Tabela 7 espelha a opinião dos congressistas quanto à filiação da ABEn a entidades internacionais. Indagados. se consideravam importante a ABEn estar filiada ao Conselho Internacional de Enfermeiros (CIE), ao Comitê Internacional Católico de Enfermeiras e Assistentes Médico-Sociais (CICIAMS) e à Federação Panamericana de Enfermeiras(os) (FEPAEN) a maioria absoluta, isto é, $816(72,4 \%)$ congressistas responderam favoravelmente. Apenas 22, ou seja $2,0 \%$ dos congressistas opinaram desfavoravelmente quanto à referida fillação. Novamente, São Paulo, Pará e Rio de Janeiro contribuíram com maior número de opiniōes favoráveis. O número dos que não responderam à questão $(20,3 \%)$ é maior do que aqueles que opinaram pela não fillação $(2,0 \%)$. Somados ambos, o resultado é de $22,3 \%$, o que não chega a representar um terço dos que opinaram positivamente, isto é, pela fillação da ABEn. Se acrescentarmos os que responderam "não sei", teremos $27,6 \%$.

O Quadro II representa o total de 3.027 alternativas assinaladas, isolada ou conjuntamente, para justificar a importância atribuída, pelo informante, à participação da ABEn em organizações internacionais. 198 questionários encontravam-se sem nenhuma alternativa assinalada a essa pergunta do questionário. Portanto, 929 questionários foram devolvidos com resposta, dando uma média de 3,3 justificativas assinaladas por congressistas. A justificativa mais assinalada, com 673 opções, ou seja $22,2 \%$ do total fol o item "apoio e assessora- mento" que os congressistas supõem que a ABEn recebe dessas entidades internacionais. Outra justificativa que encontrou muita adesão fol o item "possibilidade de participação dos associados da ABEn em congressos internacionais promovidos por essas entidades", com 554 respostas, ou seja $18,3 \%$ do total. Quinhentos e vinte e oito alternativas assinaladas $(17,4 \%)$ justificavam o. "prestígio para a ABEn" como fator que deveria nortear a filiação da ABEn a essas entidades. Trinta e três questionários $(1,1 \%)$ do total de 1.127 devolvidos estavam assinalados no item "não sei qual a importância dessa filiação". Curiosamente, quinze dos dezesseis congressistas procedentes de Mato Grosso assinalaram apoio e assessoramento como única justificativa para filliação da ABEn.

\section{Preferências dos associados por organizações internacionais}

A Tabela 8 identifica as organizações internacionais preferidas pelos congressistas. Essa Tabela se combinada com o Quadro III, pode ser analisada mais facilmente, porque $156 \quad(13,8 \%)$ informantes assinalaram duas ou três entidades. A pergunta no questionário foi elaborada, condicionando-se a resposta à concordância em pagar uma complementação de anuidade da ABEn. 473 associados, ou seja $41,9 \%$ assinalaram apenas uma das três entidades. Do total de 1.127 congressistas, noventa e seis, isto é, $8,5 \%$ são contra qualque: contribuição adicional de anuidade.

Apenas 81 congressistas $(7,2 \%)$ concordaram em que a ABEn se filiasse simultaneamente às três entidades. Entretanto, no conjunto, 629 , ou seja $55,8 \%$ do total de 1.127, optaram por uma ou mais entidades. Embora a maioria absoluta, ou seja $\mathbf{7 2 , 4 \%}$ do total de congressistas considerassem importante a ABEn estar filiada a entidades internacionais, apenas 55,8\% concordam em pagar um 
OGUISSO, T. - Opinião dos associados quanto à participação da Associação Brasileira de'Enfermagem em organizações internacionais. Rev. Bras. Ent.; DF, 33:102-120, 1980.

adicional. $402(35,7 \%)$ congressistas não responderam à questão. A entidade mais aceita pelos congressistas foi o CIE, com 375 opções $(27,5 \%)$, seguido do CICIAMS com $302(16,4 \%)$ e por último a FEPAEN com um total de 189 opções $(13,9 \%)$.

O CIE encontrou maior índice de opções em São Paulo, seguido por Pará e Rio de Janeiro. O CICIAMS é a organização preferida pela Seção Rio de Janeiro, enquanto no Pará e São Paulo essa organização foi a segunda mais assinalada.

5. Relaçāo entre exercício de cargo do diretoria da ABEn e tipo de atividade dos associados.

A Tabela 9 relaciona exercício de cargo de diretoria da ABEn com a principal função ou funções assinaladas pelos congressistas. Entre os membros ou ex-membros de diretoria da ABEn, a maioria, isto é, $45(21,6 \%)$ informantes pertencem à área do ensino, seguida da úrea de administração e assessoria com $58(18,2 \%)$ e hospitalar com $36(17,3 \%)$. Fntretanto, a maioria dos que freqüentam congressos procede da área hospitalar, com 320 associados $(36,8 \%)$ seguida de longe por aqueles cuja principal função é ensino, com 81 (10,8\%) opções.

6. Relação entre exercício de cargo de diretoria da ABEn e participa ção em congressos

Cotejando exercício de cargo de diretoria da $A B E n$ com participação em congressos, observa-se pela Tabela 10 que o fato de ocupär cargo pode ter influenciado a maior freqüência a conclaves nacionais. Entre os que ocupam ou ocuparam cargo de diretoria, a maioria, isto é, 195 ou $93,7 \%$ já haviam participado de um a 10 eventos, ao passo quee, dos que não pertenceram à diretoria, apenas 450 ou seja $51,8 \%$ o fizeram. Treze $(6,3 \%)$ dos que exercem ou exerce- ram esses cargos estavam no Congresso de Enfermagem da ABEn pela primeira vez.

Considerados os que não exercem ou exerceram cargo, quase a.metade $(48,2 \%)$ dos associados estava participando do congresso também pela primeira vez. Excluído o grupo que não havia participado de congresso algum de enfermagem até 1978, tanto entre os que pertenceram ou não à Diretoria da ABEn, a faixa de freqüência de 2 a 5 congressos foi a mais alta, com 333 associados, ou seja, $29,5 \%$ do total.

Ainda confrontando os dados entre os que exerceram cargo de diretoria com participação em congressos internacionais, verifica-se pela Tabela 11, que realmente 0 fato de pertencer ou ter pertencido à diretoria da ABEn influi na freqüência a congressos internacionais. Setenta e três, isto é, 35,1\% dos chamados membros ou ex-membros de diretoria já havia ido a pelo menos um congresso internacional, ao passo que, entre os que não exerceram esses cargos, apenas 119 , ou seja, $13,7 \%$ declararam ter participado desses eventos. Também entre os que não tiveram oportunidade de participar de conclaves internacionais, o fator "exercício de cargo de diretoria" influiu, pois os resultados são de $97(46,6 \%)$ contra 505 $(58,2 \%)$ entre os que responderam respectivamente, sim e não, ao fator acima citado. Portanto, o número dos que ocuparam cargos e não foram a congresso internacional é menor do que os que não ocuparam esses cargos e nem foram a esses congressos.

7. Relação entre exercício de cargo de diretoria da $A B E n$ e opinião quanto à filliação

A Tabela 12 mostra a relação existente entre exercício de cargo de direitoria da ABEn e opinião quanto à filiação a organizações Internacionais. $O$ 
OGUISSO, T. - Opiniāo dos associados quanto à participação da Associação Brasileira de Enfermagem em organizaçōẹs internacionais. Rev. Bras. Enf.; DF, 33:102-120, 1980.

exercício desses cargos não provocou grandes alterações no quadro de respostas, pois $80,3 \%$ dos congressistas que já pertenceram à diretoria, foram de opinião favorável à filliação, enquanto que $70,9 \%$ dos que não exerceram esses cargos também tiveram a mesma opinião. Há que se destacar que, mesmo entre os que não pertencem, nem pertenceram à diretoria da ABEn, há os delegados oficiais e os eleitos, ambos eleito pelos seus pares nas Seções e Distritos, pois estes cargos não são considerados de diretoria. Quatro congressistas (1,9\%) embora membros de diretoria da ABEn foram de opinião contrária à filliação, enquanto $18(2,1 \%)$ dos que não pertenceram à Diretoria tiveram a mesma opinião, cinco congressistas $(2,4 \%)$ e 53 $(6,1 \%)$, respectivamente entre os que ocuparam, ou não, cargo de diretoria, assinalaram o item "não sei" quanto à importância da ABEu estar filiada a organizações internacionais. Trinta e dois $(15,4 \%)$ informantes dos que ocuparam cargos e $182(20,9 \%)$ dos que não pertenceram à diretoria não assinalaram resposta alguma, por não ter opinião formada ainda, ou por não querer emitir opinião.

8. Relação entre exercício de cargo de diretoria da ABEn e preferências por organizações internacionais

A Tabela 13 indica as preferências quanto às organizações internacionais entre os que exercem ou exerceram cargo de diretoria da ABEn. Entre os membros de diretoria, a maioria, isto é, 44 $(21,2 \%)$ congressistas optaram pelo CICIAMS. Somando-se os que preferiram essa entidade conjuntamente com - CIE e/ou FEPAEN, o número atinge 82 opções $(29,4 \%)$, como mostra o Quadro IV. Em segundo lugar a preferência é o CIE, com 40 opções $(19,2 \%)$ isoladas, porém em conjunto ultrapassa as opções alcançadas pelo CICIAMS, pois é de 84 $(30,1 \%)$, conforme se pode observar no Quadro IV. Cinqüenta pessoas que já tiveram experiência de cargo de diretoria não responderam a esse item, 0 que corresponde a $24 \%$ do total de 208 congressistas que já participaram de diretoria. Entretanto, desse total, $151(67,8 \%)$ congressistas optaram por uma ou mais entidades.

Entre os que não ocupam nem ocuparam cargo de diretoria, a primeira preferência isolada é o CIE, com 180 opções $(20,7 \%)$, seguida do CICIAMS, com $134(15,4 \%)$. Somadas as opções assinaladas em conjunto, o CIE atinge 281 e o CICIAMS 211, mantendo-se, pois, a mesma ordem de classificação por opção isolada.

Somando-se as opções dos que pertenceram ou não à diretoria, o resultado é o mesmo da Tabela 8. A maioria, isto é, $227(20,1 \%)$ do total de 1.127 congressistas optou pelo CIE, seguido do CICIAMS com $185(16,4 \%)$ e a FEPAFN com $61(5,4 \%)$ opções assinaladas.

9. Relação entre nível de cargo de diretoria ocupado pelo congressista e opinião quanto à filiação

A Tabela 14 relaciona nível do cargo ocupado na diretoria da ABEn, em qualquer época, pelos congressistas e a opinião manifestada quanto à filiaçãó da $A B E n$ a entidades internacionais.

Do total de 204 informantes que já exerceram cargo de diretoria, a maioria absoluta, isto é, 162 ou $79,4 \%$ foram de oponião favorável à filiação. Apenas cinco $(2,5 \%)$ membros ou ex-membros de diretoria da ABEn a nível estadual, opinaram desfavoravelmente à filiação. Um congressista que exerceu cargo de diretoria a nível nacional e quatro, a nível estadual, assinalaram o item "não sei" quanto à importância dessa filiação, enquanto $32(15,6 \%)$ não responderam ao item. 
OGUISSO, T. - Opiniảo dos associados quanto à participação da Associação Brasileira de Enfermagem em organizações internacionais. Rev. Bras, Enf.; DF, 33:102-120, 1980.

10. Relação entre nível de cargo de diretoria ocupado pelo congressista e preferência por organizações internacionais

A Tabela 15 mostra a relação entre nível dos cargos de diretoria ocupados pelos congressistas e organizações preferidas para filiação mediante pagamento adicional.

Do total de 204 congressistas que já ocuparam cargos de diretoria da ABEn, observa-se que 137 , isto é, $67 \%$ assinalaram uma ou mais entidades.

Dezessete congresistàs, sendo duas (25\%) que ocuparam cargo a nível nacional, treze $(8,08 \%)$ a nível estadual, uma a nível municipal e outra a nível estadual e municipal, manifestaram-se contrários à filliação.

Analisando-se em conjunto, as Tabelas 15 e 8, verifica-se que 96 congressistas $(8,5 \%)$ não estão dispostos a pagar adicional a nenhuma das entidades internacionais. Se desses $96,17(8,3 \%)$ ocuparam cargos de diretoria em qualquer um dos níveis, conforme mostra a Tabela 15, significa que $79(8,5 \%)$ pessoas que não pertenceram à diretoria da ABEn são da mesma opinião, isto é, são contrários à flliação. Se $17(8,3 \%)$ informantes do grupo de 204 que exerceram cargo de diretoria e $79(8,5 \%)$ dentro do grupo de 923 dos que não ocuparam cargo algum, manifestaramse contra a filliação, significa que, o fato de pertencer à diretoria da ABEn pouco ou nada contribuiu para modificar n comportamento do congressista frente ao problema da participação dessa associação em uma ou mais entidades internacionais.

Dentre os $137(67 \%)$ membros ou ex-membros de diretoria que fizeram opção por instituições internacionais, verifica-se pela Tabela 15 , que $21,6 \%$ assinalaram o CICIAMS, $18,1 \%$ o CIE e $5,4 \%$ a FEPAEN. Somando-se opções isoladas com as conjuntas a duas ou três entidades, ainda é o CICIAMS que alcança a maioria das opções.

11. Relação entre categoria do congressista e preferência por entidade internacional

De acordo com a Tabela 16, 629 congressistas manifestaram-se a favor da fillação mediante pagamento de adicional para uma ou mais organizações internacionais. Desse total, $507(80,6 \%)$ são enfermeiros, $16(2,5 \%)$ enfermeiras obstétricas ou obstetrizes, $2(0,3 \%)$ técnicos de enfermagem, 91 estudantes de enfermagem $(14,5 \%)$ e $10(1,6 \%)$ congressistas sem identificação da profissão.

Observa-se que enfermeiros formados em 1950, ou antes desse ano, demonstraram claramente sua preferência pelo CICIAMS, tendência essa seguida também pelos formados no período 1951-60 e 1961-70. Apenas os enfermeiros mais novos, isto é, formados de 1971 em diante é que preferem o CIE. Esse grupo constitui a maioria dos elementos presentes ao congresso. Por essa razão a preferência desses últimos influiu decisivamente no total, fazendo com que - CICIAMS que liderava as opções assinaladas pelos enfermeiros formados até 1970, passasse a segundo lugar, por causa do grupo mais novo e mais numerosos que prefere o CIE.

Dos 91 estudantes de enfermagem que responderam favoravelmente a essa questão, $44(48,3 \%)$ optaram pelo CIE, $14(15,4 \%)$ pelo CICIAMS e apenas 10 (10,9\%) pela FEPAEN.

Do total de 629 congressistas, 81 $(12,9 \%)$ manifestaram-se pela filiação conjunta às três organizações internacionais. Entre eles, $63(77,8 \%)$ são enfermeiros e $13(16,0 \%)$ estudantes de enfermagem.

Dos cinco técnicos de enfermagem que responderam ao questionário, dois preferiram o CICIAMS e três não assinalaram resposta ao item. 
OGUISSO, T. - Opinião dos associados quanto à participação da Associação Brasileira

đe Enfermagem em organizações internacionais. Rev. Bras. Enf.; DF, 33:102-120, 1980.

Mesmo entre aqueles, cuja profissão não foi identificada, a preferência manifestada foi pelo CIE.

Consolidadas as opções por entidades internacionais, manifestadas de forma isolada ou conjuntamente, como mostra o Quadro V, observa-se que as preferências continuam para o CIE em todas as categorias profissionais, inclusive dos estudantes. A situação já descrita, dos enfermeiros fọrmados até 1970 e dos formados de 1971 em diante, permanece, pois no primeiro grupo as preferências são para o CICIAMS e o grupo mais jovem prefere o CIE.

Noventa e seis congressistas, dos quais $87(90,6 \%)$ são enfermeiros, opinaram favoravelmente à fillação. A falta de resposta de 402 congressistas, o que representa $35,7 \%$ dos que devolveram os questionários, constitui uma dificuldade para se definir com maior segurança as preferências dos enfermeiros.

\section{CONCLUSÓES}

De acordo com os objetivos traçados, o estudo de uma amostra constituída de $85 \%$ de uma população de 1.325 participantes que compareceram ao XXX Congresso Brasileiro de Enfermagem, em Belém do Pará, possibilita extrair as seguintes conclusões:

1) A grande maioria dos associados, em geral, isto é, $72,4 \%$, considera importante a filiação da $\mathrm{ABEn}$ às entidades internacionais: Conselho Internacional de Enfermeiras (CIE), Comitê Internacional Católico de Enfermeiras e Assistentes Médico-Sociais (CICIAMS) e Federação Panamericana de Enfermeiras (os) (FEPAEN). Se considerados apenas os associados que já ocuparam cargo de diretoria da ABEn, esse percentual aumenta para $80,3 \%$.

2) O exercício de cargo de diretoria da $A B E n$ favorece a maior participagão do associado em congressos, tanto nacionais promovidos pela ABEn co- mo internacionais promovidos pelas entidades internacionais referidas.

3) Os cargos de diretoria da ABEn são preenchidos principalmente por associados cuja principal função encontra-se na área de ensino. Entretanto, são os profissionais oriundos da área hospitalar que constituem a maior clientela que freqüenta os congressos de enfermagem.

4) Quando à época de formação profissional, observa-se que enfermeiros formados até 1970 são mais favoráveis à filiação mediante contribuição adicional ao CICIAMS, enquanto enfermeiros formados após 1971, são favoráveis ao CIE.

5) Apesar de $35,7 \%$ dos congressistas que devolveram o questionário não terem feito opção para nenhuma organização internacional, a maioria dos associados, isto é, $55,8 \%$ do total de $\mathbf{1 . 1 2 7}$ participantes opinaram pela manutenção da filiação da ABEn a entidades internacionais. Apenas 8,5\% manifestaram-se desfavoravelmente. A entidade mais votada pelos congressistas fol 0 CIE, seguida pelo CICIAMS e em terceiro lugar a FEPAEN. Do total de 629 congressistas que optaram para uma ou mais entidades, $141(22,4 \%)$ são integrantes ou ex-integrantes de diretoria da ABEn, o que vale dizer, são líderes na enfermagem, eleitos por seus pares, e portanto elementos representativos da classe e do pensamento dos associados, em geral.

A luz dos preceitos estatutários não só da $A B E n$, mas principalmente das entidades internacionais às quais está filiada; do princípio de coerência interna que deve ser resguardado quanto ao crescimento de Associações e obrigações correspondentes; e ainda, o princípio da anuidade que deve ser mantido na ABEn para assegurar sua continuidade como organização forte e livre, verifica-se que a experiência feita nas décadas de 1950-60, solicitando-se ao associado para declarar, por escrito, 
OGUISSO, T. - Opiniảo dos associados quanto à participação da Associação Brasileira de Enfermagem em organizações internacionais. Rev. Bras. Enf.; DF, 33:102-120, 1980.

a que setor ou setores internacionais desejava pertencer, pagando uma cota suplementar, poderia constituir, talvez, solução para o caso do CICIAMS, mas não para o CIE.

Há que se reiterar que o membro da ABEn não pode isoladamente pertencer ou pedir filliação a essas entidades internacionais. a ABEn que irá se fillar, ou não. E ABEn são todos os associados quites com a Tesouraria.

A solução correta e ideal, pois, seria declarar o número exato de associados às entidades internacionais $\mathrm{e}$ arcar com o ônus dessa filliação, ou então, assumir o desligamento. Essa hipótese, por sinal, já foi tentada, sem êxito, diversas vezes. Por fim, a própria ABEn acabou desistindo de solicitaçס̄es de desligamento.

A aparente irrelevância do objeto deste estudo adquire aqui um certo vulto, pois trata-se de decidir uma questão que terá repercussões em, pelo menos, oitenta e sete países, onde o CIE tem associações nacionais filladas. Historicamente, a ABEn mantém uma tradição de respeito, continuidade e força nesses cinquienta anos em que está filiada ao CIE. desde 1929. A ABEn já enfrentou crises muito mais difíceis, nas memoráveis fases heróicas, que os membros de diretoria se revezavam nas cotas de dedicação e sacrifício para manter acesa a chama de unidade e de vida da ABEn.

Também o CICIAMS, do qual é membro desde 1955, isto é, há vinte e quatro anos, dado o número de profissionais de enfermagem de religião católica, é um caso que merece muita reflexão. A ABEn tem um grande débito de gratidão às religiosas que, em épocas passadas, recentes e atuais, vem contribuindo para o crescimento da Associação. A história da ABEn registra inúmeros nomes de religiosas, como Madre Marie Domineuc, Irmã Matilde Nina,
Irmã Maria Gabriela Nogueira, Madre Maria Aurea da Cruz e a própria Irmã Maria Tereza Notarnicola, nossa atual Secretária Executiva. O Brasil já foi sede de dois congressos internacionais do CICIAMS e vem participando de outros, realizados em diferentes países, enviando representantes, como ocorreu recentemente na Costa do Marfim, na Africa.

Quanto à FEPAEN, de instituição recente e fillação da ABEn há apenas nove anos, não representa 0 maior encargo, por enquanto, porque a taxa anual é um valor fixo. Sendo uma entidade que congrega associaçōes dos países latino-americanos, a representação do Brasil, pela sua dimensão territorial e populacional, inclusive quanto ao número de profissionais formados e em exercício, constitui certamente o maior núcleo associativo da enfermagem. Insistentemente tem sido solicitado que a ABEn assuma a direção e realize um congresso da FEPAEN.

A falta de maior divulgação sobre a matéria entre os associados de um modo geral, de maior correspondência com essas entidades, além de maior participação da ABEn em reuniōes promovidas por essas entidades, têm gerado desconhecimento das responsabilidades da ABEn como membro dessas organizações.

Porém, tudo isso constiui um pesado encargo financeiro que o "per capita" enviados pelas Seções não tem conseguido cobrir. Por outro lado, anuidades elevadas dificultam o recrutamento de associados, principalmente depois da criação e implantação dos Conselhos de Enfermagem, onde a inscrição e o pagamento de anuidade são compulsórios.

Embora o Conselho de Enfermagem constitua um sinal visível da evolução da enfermagem no pais, assim como a criação dos Sindicatos de Enfermeiros, ambos frutos do empenho e esforço da própria ABEn, é possível que o nível de 
OGUISSO, T. - Opiniåo dos associados quanto à participação da Associação Brasileira de Enfermagem em organizaçōes internacionఓis. Rov. Bras. Enf.; DF, 33:102-120, 1980.

conscientização profissional e associativo dos enfermeiros, obstetrizes e técnicos de enfermagem ainda não tenha atingido suficiente maturidade para compreender a necessidade das três instituições, cada uma com seus objetivos distintos e bem definidos.

Talvez, no futuro, a fórmula ideal seja o entrosamento, quem sabe até a integração, da ABEn com o Conselho de Enfermagem, para unidos e fortalecidos, estudarem mais profundamente o problema da filiação às entidades internacionais, inclusive verificando como as associações de enfermagem de outros países solucionam o problema.

\section{RECOMENDAÇOES}

Com base na investigação realizada, recomenda-se:

\section{A ABEn:}

1) que proponha à Assembléia de Delegados que a anuidade paga pelo associado cubra, pelo menos:
a) a assinatura đa Revista Brasi- leira de Enfermagem;
b) o Boletim Informativo;
c) a cota "per capita" para enti- dades internacionais;
d) as despesas administrativas da ABEn a nível estadual e dis- trital;

e) saldo para realização de atividades sociais, culturais e outras programações previstas no Estatuto, comemorações, etc.

2) que promova maior divulgação sobre a matéria, pois até congressistas que pertenceram à diretoria da ABEn, tanto a nível central, como estadual e distrital, reconheceram não saber qual a importância da Associação estar filliada a entidades internacionais. Mesmo os itens não respondidos pode ter sido por não ter opinião formada, o que pode traduzir também falta de informação adequada.

As Seções e Distritos:

3) que procurem recrutar maior número de associados, inclusive entre os estudantes de enfermagem, promovendo ampla divulgação sobre os benefícios da união de profissionais em torno da ABEn como fator primordial para o desenvolvimento da profissão;

4) que estimulem os associados a participarem de congressos, especialmente os promovidos pela ABEn, além dos internacionais promovidos pelas entidades referidas, como um dos meios mais eficazes para o aprimoramento cultural, científico e profissional.

\section{REFERENCIAS BIBLIOGRAFICAS}

1. ABEn - Estatuto aprovado em 11.8.76 pela Assembléia de Delegados da ABEn.

2. AYRES, D. R. - Relatório sobre o XIII Congresso Quadrienal do ICN realizado em Frankfurt - Alemanha, de 16 a 24 de junho de 1965, Revista Brasileira de Enfermagem, Rio, 18(4) : 451-455, outubro de 1965.

3. CARVALHO, A. C. - Associação Brasileira de Enfermagem 1926-1976, Documentário, Rio, Folha Carioca Ed., 1976.

4. OGUISSO, T. - Relatório da Tesouraria, período 1977/1978, Revista Brasileira de Enfermagem, DF., 31(3): 372-382, Jul./set., 1978
5. PIROVANO. C. A. - Sobre o CICIANS, Revista Brasileira de Enfermagem, Rio, 14(4): 381-384, agosto de 1961.

6. RESENDE, M. A. - Sobre a ABEn, Revista Braslleira de Enfermagem, Rio, 14(4): 385-389, agosto de 1961.

7. RESENDE, M. A. - Relatório da Reuniảo do Conselho Diretor do ICN, Revista Brasileira de Enfermagem, Rio, 16(6): 462-471, dezembrs de 1963.

8. Conselho Internacional de Enfexmeliras XVI Congresso Quadrienal, 30 de maio a 3 de Junho de 1977, Toklo, Japão. Comunicado de Prensa n.: C-2, marzo 1977. 
OGUISSO, T. - Opiniåo dos associados quanto à participação da Associação Brasileira de Enfermagem, em organizaçőes internacionais. Rev. Bras. En?.; DF, 33:102-120, 1980.

\section{ANEXO I}

Prezado (a) colega

A Associação Brasileira de Enfermagem (ABEn) está promovendo estudo para viabilizar a manutenção das filliadas com entidades internacionais, uma vez que as cotas anuais que lhes devem ser remetidas constituem um ônus cada vez mais pesado para a ABEn.

Colabore conosco respondendo ào questionário, pelo que agradecemos. Não delxe perguntas sem resposta. Em caso de dúvida, fale com quem lhe entregou este questlonário.

Taka Oguisso - 1. ${ }^{\mathrm{a}}$ Tesoureira da ABEN

1. V. pertence à ABEn, através da Seção ou Distrito de $\ldots \ldots \ldots \ldots \ldots \ldots \ldots$

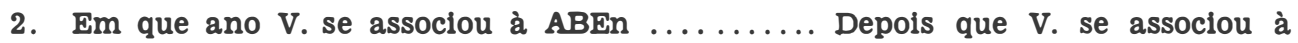
ABEn, interrompeu sua fillação alguma vez?

3. V. pertence ou pertenceu à Diretoria ou a Comissões Permanentes da ABEn?

$$
\text { SIM } \ldots \ldots \text { NAO } \ldots \ldots \ldots
$$

Em caso positivo, responda assinalando com $\mathrm{x}$ :

A nivel nacional, na ABÉn Central? ...........

A nível estadual, na Seção? .............

A nivel municipal, no Distrito?

Tendo assinalado positivamente, cite os três últimos cargos ocupados na ABEn, indicando o nível (nacional, estadual ou municipal) e respectivos periodos de mandato (em anos).

Cargo de $\ldots \ldots \ldots \ldots$ a nível $\ldots \ldots \ldots \ldots$ periodo $\ldots \ldots \ldots \ldots$
Cargo de $\ldots \ldots \ldots \ldots$ a nível $\ldots \ldots \ldots \ldots$ período $\ldots \ldots \ldots \ldots$
Cargo de $\ldots \ldots \ldots \ldots$ a nível $\ldots \ldots \ldots \ldots$ período $\ldots \ldots \ldots \ldots$

4. Assinale sua profissão e o ano de sua formatura:

Enfermeiro (a) ....... formado (a) no ano de ..........

Obstetriz ....... formada no ano de .........

Técnlco de Enfermagem ....... formado no ano de 
OGUISSO, T. - Opinião dos associados quanto à participação da Associação Brasileira de Enfermagem em organizações internacionais. Rev. Bras. Enf.; DF, 33:102-120, 1980.

Estudante de Enfermagem Nome da Escola

5. Nome da Instituição onde V. trabalha

Sua principal função ou atividade nessa Instituição é:

Hospitalar Ambulatorial Ensino Administração Assessoria Não exerce a profissão.

6. O Congresso Brasileiro de Enfermagem é realizado anualmente. Nos últimos dez anos, assinale quais em que V. participou:

1968 (Recife) . ... ; 1969 (Porto Alegre) . ...; 1970 (São Paulo) . ....... 1971 (Manaus) . . . . . ; 1972 (Belo Horizonte) .......; 1973 (João Pessoa) $\ldots \ldots \ldots 1974$ (Curitiba) .....; 1975 (Salvador) . ....; 1976 (Rio de Janeiro) 1977 (Camboriu)

7. A ABEn está filiada às seguintes entidades internacionais:

Conselho Internacional de Enfermeiras (CIE): Comitè International Católíco de Enfermeiras e Assistentes Médico Sociais (CICIAMS) e Federação Panamericana de Enfermeiras/os (FEPAEN). V. acha importante que a ABEn esteja filiada a essas entidades internacionais?

SIM NAO

NAO SEI

8. Justifique essa importância da filiação, assinalando um ou mais itens abaixo:

.... Prestígio para a ABEn.

..... Auxílio material para a ABEn.

...... Recebimento de publicações e documentos.

..... Apoio e assessoramento para a ABEn.

Possibilidade de participação dos associados da ABEn em Congressos Internacionais promovidos por essas entidades.

..... Possibilidade de participação dos associados da ABEn em concursos de bolsas de estudo promovido por essas entidades.

..... Outras. Quais?

..... Não sei qual a importância dessa filliação. 
OGUIsso, T. - Opinłáo dos associados quanto à participação da Associação Brasileira de Enfermagem em organizaşōes internacionais. Rev. Bras. Enf.; DF, 33:102-120, 1980.

9. V. já participou de algum Congresso ou qualquer outro tipo de conclave promovido por essas entidades intenacionais?

SIM ........ NAO ........

Em caso positivo, cite o ano, nome do país onde se realizou o evento e a entidade promotora (CIE, CICIAMS ou FEPAEN).

10. No caso de ser instituida uma complementação na anuidade da ABEn para os associados que quiserem manter essa fillação a entidades internacionais, V. faria opção para pertencer (assinale uma ou mais):

Ao CIE? ....... ao CICIAMS?

a nenhuma delas? ............

à FEPAEN? 